1 Centre for Gender, Health and Social Justice, University College London, UK

2 Healthier Societies Program, George Institute for Global Health, Imperial

College London, UK

Cite this as: BMJ 2022;376:0431 http://dx.doi.org/10.1136/bmj.0431 Published: 20 February 2022

\section{Social justice: what's in it for gender equality and health?}

\section{Social justice framing and approaches can help accelerate progress towards gender equality and reducing health and wellbeing inequities. Yet in addition to promoting action on the inequitable distribution of power and privilege, campaigners need to make a case for a state that proactively promotes and upholds collective wellbeing, say Sarah Hawkes, Jennie Gamlin, and Kent Buse}

\section{Sarah Hawkes, ${ }^{1}$ Jennie Gamlin, ${ }^{1}$ Kent Buse ${ }^{2}$}

Every 20 February marks World Social Justice Day in the calendar of the United Nations. For many, the idea of social justice is deeply rooted in political philosophy ${ }^{1}$ and questions of what constitutes a just and equal society and how we arrive at it. Even among proponents of social justice, belief in these core concepts of equality and fairness may be met with varying levels of acceptance depending on the type of equality demanded. In 2022, we can generally see opposition to the ideas of social justice, equality, and fairness declining, but some of the voices of resistance have radicalised, both from pushback within and against democratic states, and from the heart of nationalist and populist regimes. ${ }^{2}$ However, calls for justice that extend into demands for a universal basic income, ${ }^{3}$ a more progressive approach to land ownership, ${ }^{4}$ or a reform of immigration policies so that the right to health and life are not determined by citizenship ${ }^{5}$ are often likely to meet with resistance even among those who are generally considered progressive in their politics.

At the other end of the political spectrum, social justice is framed as a challenge to individual freedoms and has become a handy smear to imply that anything that falls under its banner is nothing more than a byword for "identity politics" and "wokeness" that constitutes a "dangerous form of decadence," ${ }^{\circ}$ as one British politician recently claimed.

Given these two starkly different positions, it is worth exploring how a social justice approach, as much in theory as in practice, can help move us towards gender equality and health and wellbeing for all. Our starting point is that gender equality and health equity are firmly intertwined, and that a social justice approach provides a much needed framework for equality of opportunity, as well as equality and equity in outcomes.

The relationship between social justice and health has been debated over many years, and for outstanding explorations of the philosophical underpinnings of social justice and health, the work of scholars such as Sridhar Venkatapuram ${ }^{7}$ and Jennifer Prah Ruger ${ }^{8}$ is well worth revisiting. Both have shone convincing conceptual lights on its centrality in promoting fair and equitable outcomes in health and wellbeing for all.

If we look at how this rich literature on health and social justice can be brought to bear on the intersection of health and gender, we think there are three areas that can spur us to greater action.
The first is the impact that gender inequality has on health outcomes. A growing evidence base ${ }^{9}$ shows the impact of gendered inequalities (or, frequently, the pervasive ignoring and overlooking of gender) on risk and vulnerability to ill health, access to health services, and the quality of care received once inside health services. Tackling these drivers of health inequities is an obvious starting point for health actors who are concerned with social justice and gender equality (for all genders).

Taking a social justice approach encourages us to think beyond the gendered inequalities apparent among people who use health services and act on the unequal and gendered distribution of power and privilege that drives health inequities more broadly. As Venkatapuram puts it, "People's health or clinical 'health outcomes' are significantly socially produced by a range of political, economic, legal, cultural and religious institutions." Thus, girls' secondary education has been estimated to be one of the two strongest predictors of maternal and health outcomes among women and girls in low and middle income countries, ${ }^{10}$ while laws against child rape "lack legal protections for boys" in 33 out of 60 surveyed countries. ${ }^{11}$ Gendered inequalities in the education and legal systems in these examples have direct consequences on the gendered distribution of health and wellbeing across all populations. Taking a social justice lens to our action on gender and health enables us to seek positive change both within the health system and across the wider determinants of health.

This message has been taken up within the global health ecosystem, with a wide variety of organisations promoting action from a social justice perspective. These range from the specifics, such as "Closing the gender pay gap is just one of the many aspects of our gender justice work around the world" (Islamic Relief Worldwide), through to more general commitments "to support the leaders, businesses and communities working for a more just and equitable society" (McKinsey and Company). Our Global Health 50/50 report ${ }^{12}$ in 2021 found that among 200 organisations across the global health ecosystem, 28 use the language of social justice in describing their work and philosophy. What we need now is for this minority view to become normalised and the dominant way of framing our work in health.

The second area where social justice is necessary relates to participation and engagement. The "revolutionary"13 Alma Ata declaration of 1978 called for the "maximum community and individual 
self-reliance and participation in the planning, organization, operation and control of primary health care." ${ }^{14}$ In the decades since, countless policies and programmes in both health and gender have incorporated community and public engagement. Such an approach fits within the philosophy of social justice-not only because it promotes individual agency, but also because it underpins exercises in reaching agreement on collective values, shared priorities, and the prevailing rules and norms in the health system. ${ }^{7}$

Last, but by no means least, it is important to recognise that social justice relies upon laws and policies that promote distributive justice, and hence on the presence of properly funded and fully functioning public institutions to ensure implementation of and accountability for those policies..$^{15}$ In other words, for social justice to be achieved we need state institutions that function for the welfare and wellbeing of all, and which can be held to account for these commitments.

While action at the levels of individuals and organisations is necessary, it is unlikely to be sufficient in achieving social justice across gender and health. We also require states, state institutions, and multistate instruments (such as the United Nations) to uphold principles of social justice and speak the language of social justice. In recent years, we have seen a constant eroding of the state (and the multilateral system) and its functions in many settings. The marketisation and financialisation of what were previously state-led services (health, education, welfare), together with a diminishing of the concept of collective wellbeing, has undermined the collective power of citizens to hold systems to account for the social good that lies at the heart of social justice.

Many of us proudly claim the moniker of "social justice warrior" when promoting gender equality and health and wellbeing for all. We propose that World Social Justice Day is as good a time as any to remind ourselves that while social justice may start with a claim to identity and representation, its full realisation means also holding democratic states to account for their duty to serve their communities by guaranteeing social wellbeing and the fair distribution of resources.

Competing interests: We have read and understood BMJ policy on declaration of interests and have none to declare.

Provenance and peer review: not commissioned; not peer reviewed.

Open Democracy. Amartya Sen and the Idea of Justice https://www.opendemocracy.net/en/amartya-sen-and-idea-of-justice/

2 Donà A. What's Gender Got to Do with Populism?Eur J Womens Stud 2020;27:285-92doi: 10.1177/1350506820929222.

3 Joseph Rowntree Foundation. Is universal basic income a good idea? 27 May 2021 https://www.jif.org.uk/universal-basic-income-good-idea

4 Monbiot G, Grey R, Kenny T, et al. Land for the Many; changing the way our fundamental asset is used, owned and governed. A report to the Labour Party. June 2019. https://landforthemany.uk/

5 León D. J. The Land of Open Graves: Living and Dying on the Migrant Trail. University of California Press, 2015

6 Mason R. Tory party chairman says 'painful woke psychodrama' weakening the west. The Guardian. 14 February 2022. https://www.theguardian.com/politics/2022/feb/14/oliver-dowdensays-painful-woke-psychodrama-weakening-the-west

7 Venkatapuram S. Health Justice: An Argument from the Capabilities Approach. Polity Press, 2011.

8 Prah Ruger J. Health and Social Justice. Oxford University Press, 2010.

9 Lancet Series on Gender Equality, Norms, and Health. Lancet. 30 May 2019. https://www.thelancet.com/series/gender-equality-norms-health.

10 Kidman R, Heymann J. Prioritising action to accelerate gender equity and health for women and girls: Microdata analysis of 47 countries. Glob Public Health 2018;13:1634-49. doi: 10.1080/17441692.2018.1427272 pmid: 29345212

11 Economist Intelligence Unit. Shining Light on the Response to Child Sexual Abuse and Exploitation. 2019. https://outoftheshadows.eiu.com/

12 Global Health 50/50. Annual Report. Gender Equality: Flying Blind in a Time of Crisis. 2021. https://globalhealth5050.org/2021-report/
13 Lawn JE, Rohde J, Rifkin S, Were M, Paul VK, Chopra M. Alma-Ata 30 years on: revolutionary, relevant, and time to revitalise. Lancet 2008;372:917-27. doi: 10.1016/S0140-6736(08)61402-6 pmid: 18790315

14 World Health Organization. Declaration of Alma-Ata. International conference on primary health care. Kazakhstan, USSR. 1978. https://www.who.int/publications/almaata_declaration_en.pdf

15 United Nations Dept of Economic and Social Affairs. Social Justice in an Open World: The Role of the United Nations. 2006; New York. https://www.un.org/esa/socdev/documents/ifsd/SocialJustice.pdf 